\title{
The Spontaneous Breathing Trial: Separating Fact From Fiction
}

It should be clear to every clinician caring for mechanically ventilated patients that a spontaneous breathing trial (SBT) is the best approach to early and successful ventilator liberation. ${ }^{1}$ It is important to make the correct decision regarding the timeliness of extubation because of the complications of a failed extubation. ${ }^{2}$

What is unclear is how to perform an SBT and how to predict successful extubation. There are a number of unanswered questions. Should the same SBT technique be used on all patients regardless of their underlying disease and duration of mechanical ventilation? Should you use a T-piece, pressure support, tube compensation, or a ventilator set for no support? ${ }^{3}$ Should CPAP be used and, if so, how much? Should the duration of an SBT be 15, 30, 60, or $120 \mathrm{~min}$ ? What criteria should be used to make the extubation decision? The answers to these questions have been debated. Many of the answers begin with an anecdote or a statement of personal bias, which is hardly an evidence-based approach.

In this issue of Respiratory CARE, Figueroa-Casas et al ${ }^{4}$ examine changes in breathing variables over the course of a 30-min SBT. This study, along with the work of Esteban et $a 1,5$ demonstrates that if breathing variables were to change during an SBT, it would most likely occur within the first $10-15$ min. ${ }^{4}$ Figueroa-Casas et al ${ }^{4}$ showed that a $\geq 20 \%$ change in breathing variables occurred after the first $10 \mathrm{~min}$ of the SBT in only $\leq 5 \%$ of subjects. This finding is intriguing, even though the sample size was too small to determine whether it might be used to predict extubation failure. The available evidence is not sufficient to support a 10-15-min SBT, but this possibility merits further investigation. As the authors suggest, the work load of clinicians is increasing, ${ }^{6}$ so the potential of a shorter and predictive SBT is attractive.

Although this study was well done, there are several limitations. First, the re-intubation rate of $22 \%$ is higher than that commonly reported. ${ }^{7}$ The other important issue not explored in this article is whether the SBT was done in

Mr Loik has disclosed no conflicts of interest.

Correspondence: Paul S Loik RRT, Adult Respiratory Care Department, University of Michigan Health System, University Hospital B1-H234, 1500 E Medical Center Drive, Ann Arbor, MI 48109-0024. E-mail: ploik@med.umich.edu.

DOI: $10.4187 /$ respcare. 03958 conjunction with a spontaneous awaking trial. The combination of these 2 strategies has demonstrated improved outcomes $^{8}$ and should be standard practice.

\section{See the Original Study on Page 155}

Although the study by Figueroa-Casas et $\mathrm{al}^{4}$ adds to the body of knowledge related to SBTs, additional high-level evidence is needed. The same effort that was placed on determining appropriate tidal volume and ventilating pressure should be used to determine the best approach to conducting an SBT. Liberation from mechanical ventilation is an everyday occurrence, and it is time to establish the evidence to support the approach we use.

Paul S Loik RRT

Adult Respiratory Care Department University of Michigan Health System Ann Arbor, Michigan

\section{REFERENCES}

1. MacIntyre NR, Cook DJ, Ely EW Jr, Epstein SK, Fink JB, Heffner $\mathrm{JE}$, et al. Evidence-based guidelines for weaning and discontinuing ventilatory support: a collective task force facilitated by the American College of Chest Physicians; the American Association for Respir Care; and the American College of Critical Care Medicine. Chest 2001;120(6 Suppl):375S-395S.

2. Epstein SK, Ciubotaru RL, Wong JB. Effect of failed extubation on the outcome of mechanical ventilation. Chest 1997;112(1):186-192.

3. Tobin MJ. Extubation and the myth of "minimal ventilator settings." Am J Respir Crit Care Med 2012;185(4):349-350.

4. Figueroa-Casas JB, Connery SM, and Montoya R. Changes in breathing variables during a 30-minute spontaneous breathing trial. Respir Care 2015;60(2):155-161.

5. Esteban A, Alía I, Tobin MJ, Gil A, Gordo F, Vallverdú I, et al. Effect of spontaneous breathing trial duration on outcome of attempts to discontinue mechanical ventilation. Am J Respir Crit Care Med 1999;159(2):512-518.

6. Ford RM. Staffing the respiratory care department: new considerations. Respir Care 2011;56(11):1864-1865.

7. Frutos-Vivar F, Ferguson ND, Esteban A, Epstein SK, Arabi Y, Apezteguía C, et al. Risk factors for extubation failure in patients following a successful spontaneous breathing trial. Chest 2006;130(6): 1664-1671.

8. Girard TD, Kress JP, Fuchs BD, Thomason JW, Schweickert WD, Pun BT, et al. Efficacy and safety of a paired sedation and ventilator weaning protocol for mechanically ventilated patients in intensive care (Awakening and Breathing Controlled trial): a randomized controlled trial. Lancet 2008;371(9607):126-134. 